\title{
E-tivities and the connecting of e-learning experiences through deliberative feedback
}

\section{James Slevin}

Ph.D. Cantab.

Amsterdam School of Communications Research

University of Amsterdam

James.Slevin@jslevin.org

http://www.jslevin.org

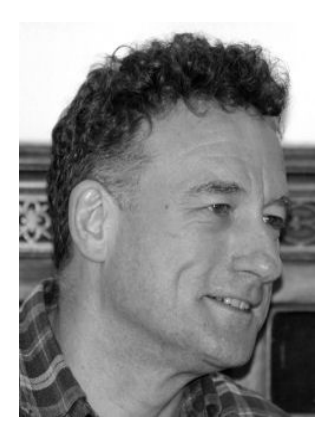

James Slevin is author, academic and consultant. He is an adjunct professor at the Institut for Kommunikation, Journalistik og Datalogi, Roskilde University and member of the Amsterdam School of Communications Research, University of Amsterdam. His interests are social theory; social aspects of communication and modern culture, with particular reference to the social impact of the internet and related networks; and e-learning. This article is based on experiences gained during teaching for the Master of Computer-Mediated Communication at the Roskilde University and for the Masters in Public Policy and Management at the University of York - both of which are delivered using e-learning.

\section{E-learning has become a key source of expansion and competition in education}

Learning lies at the heart of modern society. 'How am I doing? '; 'What have I learnt from this? ' and 'How might I do things differently in the future?', are questions that accompany almost everything we do. The reason for this is that successful intervention in our world today, is increasingly governed by decisions that are made on the basis of knowledge and competence which is revisable or can be rendered outdated in an instant. Under such circumstances, learning becomes a chronic and absolutely necessary feature for negotiating a balance between failure and gain.

Communication is an important part of the total process by which the acquisition of skills and knowledge proceeds. For a long while, this process took place predominantly during face-toface encounters and supervision. From the nineteenth century, due to the rise of mass literacy and the industrialization of printing, forms of mediated interaction, like textbooks and schoolbooks, come to supplement face-to-face communication in education (Vincent, 2000). The development of modern postal communications and the emergence of various types of electronic media, such as radio and television, vastly extend the opportunities for mediated learning.

Over the past decade, e-learning is emerging as a key source of expansion and competition in education. Proper uses of net-media like the internet, contribute to learning becoming vastly more decentred as well as all-embracing in contrast with what went before (Giddens, 2001, pp. 490-526). Training and the acquiring of qualifications can now happen at any time and in any place. The once separate phases of an education taking place early on in life and a 
subsequent 'career' have become blurred. The separating out of classrooms and lecture halls from other physical settings as the primary places of learning has also come to an end. Today, e-learning gives rise to a continuum of interactional situations: from courses that are predominantly face-to-face with some online interaction, through blended courses with online interaction supported by some face-to-face interaction, to courses that take place almost wholly online. Due to the opportunities created by e-learning, many people are now attracted to training and education who would not have before considered it possible or even relevant to their lives.

\section{Some challenges for institutions of learning}

In this new educational environment, radical societal transitions and the new opportunities afforded by modern communications technologies, snap together to produce some formidable challenges for institutions of learning. In this setting, what is dubbed the 'scholarly communications crisis', is by no means comprehensively defined by the misgivings of librarians. They are merely up in arms over the spiraling costs of accessing information and the constraints placed on the use of digital content by commercial publishing houses (Wadham, 2003, p.23). Of course, librarians raise an important issue: modern communication technologies do radically alter the amount of control individuals and organizations have over the transmission of information and communication.

However, a world in which nothing is certain and in which the traditional scholar-teacher relationship is being radically redefined, gives birth to worries of a more embracing nature. We need to extend the concerns about a 'scholarly communications crisis' and ask: how can institutions of learning best deploy modern communication technologies in order to engage and interact meaningfully with those seeking knowledge, guidance and, above all else, inspiration? This is a daunting question, as Ronald Barnett (2000) explains with a particular concern for higher education, which he argues,

... is faced not just with preparing students for a complex world but is faced with preparing them for a supercomplex world. It is a world where nothing can be taken for granted, where no frame of understanding or of action can be entertained with any security. It is a world in which we are conceptually challenged, and continually so. (p. 257)

As if this were not enough of a challenge, in the new information and communication environment, institutions of learning find their once unquestioned authority to educate, no longer accepted. Addressing this issue, Zygmunt Bauman (2001) writes,

It was the opening up of the information superhighway that revealed, in retrospect, just how much the claimed, and yet more the genuine, authority of the teachers used to rest on their collectively exercised, exclusive control over the sources of knowledge and the no-appealallowed policing of all the roads leading to such sources. It has also shown to what extent that authority depended on the unshared right of the teachers to shape the 'logic of learning' - the time sequence in which various bits and pieces of knowledge can and need to be ingested and digested. (pp. 130-131)

Exploring the extent of the 'scholarly communications crisis' even further still, involves acknowledging that the opportunities and risks involved in using net-media in education are not yet well understood (Segers, 2002, pp. 32-34). Virtual learning environments are often treated as being no more than an efficient technological means for the storing, circulating and retrieving of such matters as: lecture handouts, webcasts, podcasts, course schedules, essay questions and answers. E-learning is thus reduced to merely being an alternative channel for the distribution of educational communication and information. Online communication in teaching and learning in this fashion, can simply be taken to mirror what traditionally goes on in a class or in a lecture room. Such a poor understanding of the often contradictory 
implications of using e-learning technology also clears the way for such technology to be uncritically seen and accepted as a magical tool, or a technological fix, posited a priori as being the solution to many educational ills (Clegg, Hudson, \& Steel, 2003, p. 49).

Attempts at shifting away from this uncritical pose are not always helped by the way in which the software and training industry approach e-learning technology. Here, promotional events are held, such as "product shootouts", during which contestants are invited to compete for a period of twenty minutes in using various software systems to convert PowerPoint presentations from classroom to e-learning use (Chapman, 2003, pp. 40-42). Similar to this line of thought, e-learning is considered to be more student-centered than traditional classroom teaching solely because students engage actively with the learning technology.

In all of this, the extent to which e-learning can create opportunities for new forms of action and interaction in education, is seriously underestimated. As a consequence, teachers become increasingly convinced of the impracticalities of e-learning (Hartman, Lewis, \& Powell, 2002, pp. 9-28) and learners become ever more disillusioned by not getting an education with a use and enabling power that they feel that their lives now require.

\section{Rethinking the role of communication technology in late modern education}

There are no simple solutions to all these challenges. What is clear though, is that there is a need to rethink and articulate anew the role of communication and its technologies in late modern education. My central aim in this article is to elaborate some important issues in communication and education which might help us come to terms with the impact of netmedia on learning. I shall pursue this aim in three steps. First, I shall set out three significant developments in social, education and communication theory that are beginning to converge in new ways of attending to e-learning. Second, I shall demonstrate this by examining how these three developments can be seen to interlock in e-learning, by focusing on what Gilly Salmon calls: 'e-tivities' and the 'five-stage model of teaching and learning online' (2002). Lastly, I shall carry these arguments through in elaborating one of the most important aspects of communication and interaction in learning: the giving and receiving of feedback, and explain and demonstrate how this is transformed in the process of what Gilly Salmon calls ' $e$ moderating' (2000; 2003) or teaching online.

\section{Three significant developments in social, education and communication theory}

The transitions taking place in everyday life and in the distinctive qualities of social organization over the past four or five decades, have triggered significant ongoing reflection and rethinking in social, education and communication theory. Three sets of developments are beginning to converge in new ways of attending to e-learning. First, in social theory we see the development of generative approaches to risk and uncertainty. Second, in education theory we see the development of generative approaches to the changing demands of teaching and learning. Third, in communication theory we see the development of generative approaches to the ways in communication technologies facilitate a reorganization of information and interaction across time and space. Let us look at each of these in turn.

\section{Anthony Giddens: Risk and uncertainty demands our active engagement}

Ulrich Beck and other social theorists draw our attention to risk and uncertainty as being ubiquitous features of late modern society (Beck, 1999). However, as some social theorists claim, risk is not necessarily a bad thing. Many new opportunities go along with risk and there is a big difference between, on the one hand, passively experiencing and, on the other, 
fostering of a positive engagement with risk. A positive or generative approach to risk allows individuals and organizations to actively explore risk environments and draw on the energizing principle of risk in late modern societies (Giddens, 1998, p. 63). Living in a world in which knowledge and competence are revisable or can be rendered outdated in an instant, demands our active engagement. Anthony Giddens explains that fostering such a generative approach to risk and uncertainty involves four areas of concern both on the level of individuals and on the level of their broader institutional contexts (1994, pp. 1-20). First, how might we facilitate and encourage intelligent relationships between organizations, groups and individuals, which are ordered through dialogue rather than through the exercise of traditional authority which we no longer necessarily trust?

Second, how might we empower organizations, groups and individuals to make things happen rather than to have things happen to them, in the context of overall goals?

Third, how might we restore solidarity, which can no longer be guaranteed by traditional means, and bring together organizations, groups and individuals who were hitherto geographically and socially far apart?

Fourth, how might we develop cosmopolitan attitudes, making beneficial the consequences of people crossing paths with others whose interests may differ from their own?

Individuals living and working in late modern society, Giddens argues, need to be able to protect themselves against the negative consequences of risk, but also to be able to develop the capability to face and take risks in a creative and proactive fashion. Institutions of learning must adjust to these new circumstances. Individuals cannot simply be left to their own devices in dealing with these four areas of concern.

\section{Zygmunt Bauman: Learning how to break the regularity}

Evidence of a transition in the way learning is approached in education in the face of the challenges Giddens sets out, can be found in Zygmunt Bauman's essay: "Education: under, for and in spite of postmodernity" (2001). In this essay, Bauman draws on the work of Margaret Mead (1964) and Gregory Bateson (1973) to elaborate and discuss three degrees of learning. First degree learning concerns the content of learning. It is the message that is conveyed by the teacher to the learner. The message can 'be seen with a naked eye, monitored and recorded...' (p.123).

Second degree learning, Bauman continues, is about 'learning to learn'. It is 'so to speak a subterranean process, hardly ever consciously noticed and even less frequently monitored by its participants...' (p. 124). By way of second degree learning, learners '... acquire skills incomparably more important for their future life than even the most carefully preselected bits and pieces of knowledge ...' (p. 124). Without second degree learning, first degree learning 'would result in a desiccated and ossified mind incapable of assimilating a changed situation, or simply one unthought of in advance' (p.124).

Finally, third degree learning, results where learners acquire the skills to modify the set of alternatives which they learned to expect and handle in the course of second degree learning (p.124). Learning of the third degree, Bauman explains, is about '... learning how to break the regularity, how to get free from habits and prevent habitualization, how to rearrange fragmentary experiences into herefore unfamiliar patterns while treating all patterns as acceptable solely “until further notice”...' (p.125). In late modernity, Bauman argues, third degree learning '... acquires a supreme adaptational value and fast becomes central to what is indispensable "equipment for modern life”' (p.125).

The changing demands placed on the educational system in late modernity, are also reflected in the shift from direct instruction, which is more prevalent in traditional teaching, to more 
constructivist approaches to teaching (Bruner, 1990). Direct instruction tends to be teachercentered. Here, learning is deemed to progress by way of the teacher telling and showing. The teacher's role is that of director and executive of learning. During direct instruction, the learner's role is constrained to passively receiving the information that they will need in life.

Constructivist approaches to teaching are learner-centered. Learning is deemed to progress by way of the active involvement of learners in the construction of meaning and knowledge.

Meaning and knowledge are approached as constructed in specific contexts and are thus not given but uncertain. The teacher's role is that of facilitator and manager of learning. Teaching is not seen as a 'from' 'to' affair - from teacher to learner. Learning is understood to be an interactive and collaborative process in which learners are encouraged to be responsible, autonomous and critical, and go beyond any information that they are given.

The very antithesis to traditional direct instruction, for example by way of lectures, can be seen in the emergence of so-called problem-based learning. As Maggi Savin-Baden (2000) explains,

The focus here is in organizing the curricular content around problem scenarios rather than subjects or disciplines. Students work in groups or teams to solve or manage these situations but they are not expected to acquire a predetermined series of 'right answers'. Instead they are expected to engage with the complex situation presented to them and decide what information they need to learn and what skills they need to gain in order to manage the situation effectively... students are offered opportunities, through problembased learning, to explore a wide range of information, to link the learning with their own needs as learners and to develop independence in enquiry... increased understanding and examination of perspectives and frameworks is encouraged through problem-based learning because it offers students opportunities to examine their beliefs about knowledge in ways that lecture-based learning and narrow forms of problem-solving learning do not. (p. 3)

In Manuel Castells's work: The Internet Galaxy (2001), the development of generative approaches to the changing demands of teaching and learning get connected through to the internet. Castells writes:

'The e-conomy cannot function without workers able to navigate, both technically and in terms of content, this deep sea of information, organizing it, focusing it, and transforming it into specific knowledge, appropriate for the task and purpose of the work process... This has extraordinary consequences for the demands placed on the education system... an e-conomy requires the development of e-learning as a durable companion of professsional life... The most important feature of this learning process are, first, learning how to learn... secondly, having the ability to transform the information obtained from the learning process into specific knowledge' (pp. 90-91).

\section{John Thompson: The impact of new communication technologies}

The rise of the new communication technologies used in e-learning is not accidental to the conditions of late modernity (Rantanen, 2005). Such conditions are the result of developments for which the new communication technologies are essential tools (Slevin, 2000, p. 54). Faced with the transitions taking place in education, it's not difficult to be somewhat optimistic about the opportunities e-learning technology offers (Clegg, Hudson, \& Steel, 2003). However, neither the generative approaches to uncertainty, nor the generative approaches in education theory, provide us with concepts or frameworks that can be placed in the service of a critical understanding of the interactional impact of e-learning technology. For this, we need to turn to parallel developments in communication theory. 
The challenge of understanding the interactional impact of modern communication technologies in education, is to avoid technological determinism - as in: e-learning technology as a 'technological fix' - while opening up new horizons for understanding how such technologies, in Raymond Williams's words, 'can be used to affect, to alter, and in some cases control our social process' (1961). The development of such a generative approach to elearning technology is crucial, because it says something about how e-learning technologies facilitate a reorganization of information and social relationships in teaching and learning across time and space. One of the most comprehensive statements to propel us in such a direction is put forward by John Thompson in his studies of mass communication (1990; 1995) and is later extended to studies of the internet (Slevin, 2000).

Thompson claims that mediated interaction between producers and receivers of information involves a range of features that can be examined under the heading of cultural transmission (1990, pp. 164-165). At the heart of Thompson's approach, is the assumption that communication technologies are never simply alternative means of distribution but allow for the creation of new forms of action and interaction. Thompson argues that a critical understanding of the social impact of a particular medium, calls for it to be rigorously conceptualized as a 'modality of cultural transmission' (p. 165). As such, it combines three aspects: First, the 'technical medium of transmission' provides the material conditions by virtue of which information is stored and circulated, and which link it to particular skills, faculties and resources that are required for its use (pp. 165-167). Second, the 'institutional apparatus of transmission' sets the institutional arrangements within which a medium is used (pp. 167168). Third, the 'time-space distanciation of transmission' refers to the nature and degree of distancing and extension of availability a medium affords, across time and space. What we now mark out as e-learning can best be understood as a range of phenomena and actions using e-learning technology in education. In each case, the aspects of e-learning technologies seen as modalities of cultural transmission, are combined and developed in different ways, to produce very different learning and teaching experiences.

Thompson's theory draws our attention to the dual potentialities of communication technologies, referring as they do to the capability of the same technology to produce one set of effects or their opposite (Walton, 1989, pp. 26-28). A Virtual Learning Environment deployed in an institutional setting which is predominantly teacher-centered, will be used to store and circulate information in different ways, and require different skills from teachers and learners, than one deployed in an institutional setting which is predominantly learnercentered. Yet even in a highly teacher-centered setting, lecturers soon realize that simply storing and making available traditional face-to-face lectures by means of a Virtual Learning Environment will not do. They have to learn, in Thompson's words, to act for distant others (1990, pp. 230-232) and produce and stage their lectures so that their message gets across. They also have to learn to act in response to distant others (1990, pp. 232-235) and deal, for example, with the ‘inbox shock’ (Hartman, Lewis, \& Powell, 2002, pp. 9-28). Similarly, in a highly learner-centered setting, teachers soon realize that simply moving face-to-face classroom discussion to an online 'conversation writ large' by means of a Virtual Learning Environment will not do either. The challenge of making such interactional arrangements a success lies in finding ways of using e-learning technology to enhance the scope of deliberative processes.

\section{E-tivities}

One of the many ways in which teaching and learning is being transformed by the deployment of e-learning technology, is through the organization, design and delivery of online collaborative learning activities (Sloman, 2001, pp. 149-158). An example of this comes from Gilly 
Salmon, who has developed a framework for online collaborative learning activities that she calls: e-tivities (2002). I want to try to show that the convergence of the three developments in social, education and communication theory with the practical challenges of teaching and learning online, is evident in Salmon's work. Such an analysis provides us with significant insights concerning the implications of the impact of net-media on education and can be put in the service of a more critical understanding of e-learning.

\section{Active and interactive online learning}

An e-tivity, Salmon explains, is 'a framework for active and interactive online learning' (2002, p. 1). An e-tivity involves two, or as many as twenty participants, working together over time - mostly asynchronously - posting messages to an online discussion forum which is facilitated by an e-moderator (p. 4).

E-tivities come in many guises but they have some common features, which according to Salmon, include (pp. 87-112):

1. An engaging title.

2. A provocative or challenging piece of information: the 'spark' that ignites the activity.

3. A set of learning goals that describe the purpose of the e-tivity.

4. An instructional message on how to participate. For example, one that invites participants to post at least one contribution to the discussion and respond to at least one other contribution made by someone else.

5. A list of reading or other relevant resources.

6. An instructional message stating what participants should do.

7. An instructional message explaining the role of the e-moderator.

An online course, organized along these lines, will ordinarily consist of a string of interrelated e-tivities. An entire online learning program will ordinarily consist of an array of interrelated online courses consisting of a range of e-tivities. Salmon argues therefore, that the design and delivery of an e-tivity does not stand alone, but should be understood as embedded in a wider framework. She attempts to capture this wider framework in her: 'five-stage model of teaching and learning online'. She argues that each stage in the model involves the development of different skills and degrees of competence on the part of the learner and that this, in turn, requires different kinds of e-tivity to achieve these goals (pp. 10-36; 102-105). Let us look at each of these stages.

Stage one involves e-tivities that concern access and motivation. Here, e-tivities are designed to motivate learners to participate and explore the online learning environment and tease out any problems they may have accessing the system or with technical skills (pp. 12-19). Stage two involves e-tivities that concern online socialization. Here, e-tivities are designed to allow learners to develop and explore their online identities, bond and work together (pp. 20-24). Stage three involves e-tivities that concern information exchange. Here, e-tivities are designed to encourage participants to co-operate and to share information that will deepen each other's understanding and assist each other in reaching goals (pp. 24-28). Stage four involves e-tivities that concern knowledge construction. Here, e-tivities become progressively more reflective. Participants may be instructed to consider different viewpoints and perspectives and draw on practical experiences. E-tivities at this stage may also provide room for incurporating participant-led goals and objectives, and ways of working (pp. 29-33). Finally, stage five involves e-tivities that concern development. Here, e-tivities encourage participants to develop self-insight, pursue personal goals, reflect on their new experiences and knowledge and look beyond the forum (pp. 33-36). 
Salmon's five-stage model of teaching and learning online does not only have a bearing on the spread of different kinds of e-tivity over a single course. She argues that it is also meant as guide to the timing and spacing of e-tivities over an entire learning program. Stages one and two will receive more emphasis early on in a learning program, while stages four and five will be given more prominence as the learning program progresses (p. 10).

\section{E-tivities and an active engagement with risk and uncertainty}

Although Salmon brings her writings to life with many concrete examples of e-tivity use, her main concern is not so much with the content of teaching, but with a systematic elaboration of a method of structuring online education in late modernity. To use Margaret Mead's words, the challenges of late modernity, together with the structuring of online interaction through etivities, '.. . determine far beyond the actual content of the learning both how individuals will learn to think and how the store of learning, the sum total of separate pieces of skill and knowledge... is shared and used' (1964, p. 79). What I shall demonstrate here, is that embedded in the properties of e-tivities and the five-stage model, are the rules and resources which lend systemic form to the inculcation of an active engagement with risk and uncertainty.

The structuring consequences of using e-tivities differ from earlier forms of stratification based on traditional face-to-face classroom teaching, in four ways. First, e-tivities facilitate and encourage intelligent relationships between learners and other learners and between learners and teachers. Learners learn how to learn from their reflexive engagements with other learners and teachers learn to learn from their interaction with learners.

Second, e-tivities empower learners to learn that rather than learning being something that happens to them, it's a process in which they have an active role. Teachers too, are empowered because the use of e-tivities fosters conditions under which they learn how to promote desired learning outcomes without determining those outcomes from the top. This provides them with new opportunities for discovering how to build trust into their interaction with learners and enhance the legitimacy of their authority. Moreover as Salmon explains, e-tivities are cheap, easy to try out and to change and are ' ... in the hands of the educators' (2002, p. 3).

Third, e-tivities encourage participants to learn to develop strategic alliances and solidarities. Traditional classroom communities approximate what Michael Oakeshott terms 'compulsory associations', 'because the relationships they constitute are those recognized by the authority of common purposes and in terms of the authority of managerial decisions which specify how common purpose should contingently be pursued' (1975, pp. 315-316). Teachers and learners working on e-tivities, however, do so in ways that respect each other's autonomy - this is what makes their relationship intelligent. Consequently, individuals who are associated in this way are not teachers and learners in a relationship determined by common goals, they are related in 'terms of practice' (p. 122). The efficiency of these new ways of teaming up can no longer be measured in terms of learning goals alone, but needs to be evaluated in terms of 'their capacity to share in a give and take experience' (Dewey, 1917, p. 120).

The fourth way in which the structuring consequences of using e-tivities differ from traditional classroom education and contribute to the inculcation of an active engagement with risk and uncertainty, is that the structuring qualities of the rules and resources embedded in e-tivities promote cosmopolitan attitudes. Collaborative work on e-tivities, drawing on Giddens's words, emphasizes '.. . the responsibility that individuals and groups have for ideas they hold and the practices in which they engage’ (1994, p. 130).

\section{E-tivities and learning beyond the content}

Salmon's framework for active and interactive online learning, epitomizes many of the changes and shifts in education which I signaled earlier. First, in promoting learning beyond 
the content of learning, e-tivities embrace the increased significance of third degree learning as noted by Bauman. In doing so, e-tivities allow for the reappropriation of the kind of knowledge and skills, which are the 'indispensable "equipment for modern life”' (2001, p. 125).

Second, in recasting the roles of the teacher and the learner, e-tivities reflect the late modern shift from direct instruction to a more constructivist approach to teaching and learning. The role of a teacher in Salmon's framework is very much that of a facilitator and manager of learning. The role of a learner changes to that of a participant, with an active involvement in the construction of meaning and knowledge. This is even more so, in the later stages of her five-stage model.

Third, e-tivities bear much resemblance to the problem-tasks and problem-scenarios that learners tackle in problem-based learning. Salmon's 'spark' is akin to Savin-Baden's 'complex situation', both tempt learners to become actively involved in learning to learn within a well-structured context of facilitation.

Fourth, e-tivities are a way of attending to the demands which, Castells claims, accompany the rise of the network e-conomy and society. E-tivities, and particularly so in stage four of Salmon's five-stage model, contribute to participants acquiring the ability to navigate, organize and transform information into specific knowledge. Moreover there is a double relevance here: in using the communication technologies involved in e-learning and in learning to deal with the information environments they help create, participants are learning to deal with the very challenges of late modernity for which these technologies are essential tools.

\section{E-tivities and the impact of communication technology}

Salmon does not treat communication technology involved in e-learning simply as a way to create new channels of information circulation that exist alongside pre-existing channels of communication in education. Online collaborative learning in the form of e-tivities, embraces e-learning technology as a medium of cultural transmission. For Salmon, e-learning technology allows for the creation of new forms of action and interaction in education. First, unlike the use of PowerPoint slides to communicate in a face-to-face lecture, the use of an e-learning discussion forum allows both e-moderators and course participants to store information that can be exchanged. The storage of information in the discussion forum enables content to be preserved for future use and acts as a resource for reflexivity, allowing e-moderators and participants to move back and forth between current and past discussions.

Second, the two-way flow and circulation of messages in a discussion forum radically alters the conditions for information exchange between teachers and learners and between learners. E-tivities are designed to exploit this increased capacity of participants to influence and intervene in the process of learning and engage in 'concerted forms of responsive action' (Thompson, 1990, p. 233). E-tivities work because e-learning technology allows teachers and learners to question one another and observe one another's responses.

Third, using an online discussion forum radically alters the nature and extent of the participation that is required both in teaching and learning. E-tivities and the five-stage model recognize that both e-moderators and participants need to utilize skills that are very different from the ones used in face-to-face traditional classroom settings. Some e-tivities, for example, are geared to deal with sorting out problems to do with access and required technical skills. Others are aimed at online socialization and at encouraging participants to share knowledge and information.

Fourth, e-tivities and the five-stage model provide a set of mechanisms which circumscribe the flow of interaction taking place in the discussion forum. Such institutional arrangements restrict the implementation of e-learning technology for the sole pursuit of distributing course 
announcements, lecture transcripts and essay questions that, in turn, solicit essay-type answers that can be dealt with in an actuarial way.

Fifth, e-tivities and the five-stage model acknowledges and exploits the extension of availability over time and through space that e-learning technology affords. E-tivities can be carried out without the need for participants to be co-presence in space. Moreover, unlike classroom interaction which can be carried out within a relatively short time-span, the time schedule of an e-tivity has to allow sufficient scope for reading, reflecting on what needs to be done, writing and posting contributions, reading and reflecting on contributions and responses written and posted by others, writing and posting responses to others, reflecting on the results of the e-tivity and relating these to what needs to be done next.

\section{E-moderating and deliberative feedback}

One of the most important aspects of communication and interaction in teaching and learning is the giving and receiving of feedback. However, acknowledging the challenges of late modernity and realizing that the adaptive value of third degree learning is becoming all the more evident, Bauman (2001) writes,

'Preparing for life' - that perennial, invariable task of all education - must mean first and foremost cultivating the ability to live daily and at peace with uncertainty and ambivalence, with a variety of standpoints and the absence of unerring and trustworthy authorities; must mean instilling tolerance of difference and the will to respect the right to be different; must mean fortifying critical and self-critical faculties and the courage needed to assume responsibility fore one's choices and their consequences; must mean training the capacity for 'changing the frames' and for resisting the temptation to escape from freedom, with the anxiety of indecision it brings alongside the joys of the new and the unexplored. (p. 138)

Such qualities can hardly be comprehensively developed through feedback which is more suited to the controlling powers of teachers: by way of the transmission of the explicit content of first degree learning and by way of the rigid assessment of knowledge thereof.

I shall now carry my arguments concerning the impact of net-media on learning through in elaborating some of the opportunities for transforming feedback in e-learning. Building on my analysis of recent developments in social, education and communication theory, I shall first attempt to delineate some general opportunities for transforming feedback in online collaborative learning. I shall then use these general opportunities to elaborate the role of feedback in Gilly Salmon's work on 'e-moderating' (2000; 2003) or teaching online, which complements her work on 'e-tivities'.'

\section{The refashioning of feedback in e-learning}

We live in a world where who we are; what we do and the way we do things together are all reflexively made. Consequently, feedback processes have become inescapable features of our lives. One way of understanding feedback, is to say that it refers to the consequences of a process that are systematically incorporated as conditions which have a capacity to regulate further consequences. As a concept, feedback originated in the field of electrical engineering and has later been appropriated by other fields, such as biology and sociology, to refer to a variety of recursive mechanisms. With regard to using the concept of feedback in the social sciences, however, Giddens and other social theorists, signal the importance of distinguishing between feedback applicable to mechanical and biological systems and '... feed-back system processes from a "higher” order of reflexive self-regulation in social systems’ (Giddens, 1979, 
p. 75). In social interaction, they argue, feedback should not be understood in a too mechanical way.

In education, feedback processes play a central role because through feedback, individuals and groups can become reflexively aware of the consequences of their interventions in the world and develop knowledge and skills that may allow them to transform those consequences in the future (Giddens, 1984, pp. 14-16). In late modernity, feedback in education has taken on a new significance for a number of reasons. First, individuals and groups continually find that the application of existing knowledge and skills no longer allows them to produce required and expected outcomes. Second, modern life has become saturated with sources of information and authorities offering feedback. Third, new communication technologies, such as those used in e-learning, are creating new ways of reflexively monitoring the outcome and conditions of action and interaction, and new conditions for the producing and receiving of feedback. Against this backdrop, online collaborative learning activities are full of new opportunities for transforming the nature and role of feedback in education.

First, the development of an active engagement with risk and uncertainty can become an important part of the 'subject matter' of feedback in e-learning. Both the discursive content and the practical activities of feedback can be geared into the fostering of intelligent relationships, empowerment, strategic alliances and cosmopolitan attitudes.

Second, while feedback will continue to attend to the content of e-learning, feedback concerning second and third degree learning can acquire a more prominent role in online collaborative learning activities. Moreover, in stimulating the processes of learning to learn and learning to deal with the unexpected, the adoption of more constructivist approaches to teaching online, result in feedback not being just a matter between teacher and learner: feedback can become a key feature in the interaction between learners. The giving of feedback can itself become a learning experience. Feedback through formal assessment can also, in time, be refashioned to reflect learner-centered teaching and reflect the skills developed and used in second and third degree learning. In this respect, e-learning opens up new opportunities for participants to engage in self-assessment and peer review exercises focusing on, for example, portfolios containing participants' best contributions to online collaborative activities.

Third, the use of new communication technologies also has implications for the nature and role of feedback in online collaborative learning activities. An online discussion forum radically increases the resources that are available to teachers and learners for generating and employing feedback to manage and steer the activity of learning. All interaction is stored and can be retrieved and reflected on instantaneously or at a later time. Virtual Learning Environments generate vast amounts of experiential data, providing information on user activity which can be managed, scrutinized and made selectively available to teachers and learners. An online collaborative learning activity allows for the ongoing reflexive monitoring of activity. Feedback processes can thus be routinely incorporated as part of the flow of activity rather than as incidental happenings. Ongoing reflexive monitoring also empowers users to engage routinely in self-feedback. The creative use of anonymity and role-play opens up opportunities for participants to float different ideas and to solicit and experience 'inconsequential' feedback. The separation of interaction from a shared physical space, such as a classroom, affects the way participants present themselves and manage discussions. In text-based online discussions, there is an absence of direct and continuous feedback of either a visual or an oral kind. Deprived of immediate feedback, there is a degree of indeterminacy in online communication using discussion fora. Those posting messages are never completely certain as to how their messages are received. This can result in misunderstandings and tensions in online communication. Finally, one of the most important features of discussion fora is that they 
create a new 'space of the visible' where participants can craft their identities, construct their learning biographies, post their contributions, negotiate feedback and trace its development rather than experience feedback as something that happens to them. As such, feedback becomes an ongoing process which is open-ended, orientated towards the future and towards what needs to be done next, rather than being a closed and fleeting comment on the past. Along these lines, an online discussion forum can create new opportunities for tracking whether or not feedback made a difference and can act as grounding for calling participants to account.

With regard to the new learning arenas produced and sustained by the technologies of elearning, teachers and learners are able to engage with one another in a way and on a scale that never existed before. However, it is important to emphasize that the new opportunities for feedback processes created by discussion fora, should not be modelled as part of a 'conversation writ large' between teachers and learners. Just as the conditions of traditional face-to-face lectures shape, for the larger part, the one-way flow of messages from the lecturer to the audience, an online discussion forum also creates conditions that limit the kind of feedback that online learners can hope to receive. Here it is useful to consider the idea of 'deliberative feedback' which shifts our attention from the traditional, monopolistic and privileged role of feedback exercised by virtue of a teacher's authority, to the processes by which feedback is formed and negotiated. Much like in the formation of public opinion in Thompson's conception of 'deliberative democracy' (1995, p. 255), the process of deliberation in elearning, is itself crucial to generating useful and critical learner-centered feedback in late modern education. Thompson writes: 'The process of deliberation is necessarily open-ended. As more information is made available and as individuals consider the arguments and claims advanced by others, they may question and gradually modify their original views. The horizons of their understanding may be broadened as they strive to take account of the points raised by others' (p. 255).

\section{E-moderating}

In E-moderating, Salmon sets out to tackle the problem that teaching and learning online using e-tivities requires new kinds of teachers (2000; 2003). She refers to these as emoderators (2003, p. 10). The role of the e-moderator is different from the one that is often associated with a traditional teacher or assessor (p. 47). She writes: 'The essential role of the e-moderator is promoting human interaction and communication through the modelling, conveying and building of knowledge and skills' (p. 4). She continues: 'It is important to try to model (rather than teach) the desired skills, offer real practical experience and many opportunities for challenge, collaboration and reflection' (p. 83). Salmon's modelling, using Bauman's terms, is '... modelling without the model to be arrived at in the end being known or clearly visualized’ (2001, p. 139). As such, Salmon's work on e-moderating provides us with glimpses of the way in which feedback is transformed in the process of teaching online.

Salmon is adamant that: 'Most learners crave teachers' responses to their coursework and their examinations. Learners see the quality and quantity of feedback on their work as an important part of their relationship with their professors and educational provider' (p. 113). Considering the expertise of online teachers, Salmon writes: 'E-moderators do not need to be subject experts... If they are used to being considered an "expert" in their subject, they may find the levelling effect and informality of conferencing very challenging to start with... Stepping down from the "spotlight" and into the virtual world can be hard... Conversely, students used to the paradigm of teacher as the instructor may expect a great deal of input from the e-moderator... The e-moderator must explain his or her role at the start, to reduce the chances of unreasonable expectations arising' (pp. 56-58). "An always on, broadband tutor" (p. 23) is not only impractical, according to Salmon, it also flies in the face of the exigencies of learner-centered teaching. On the whole, e-moderators should avoid ' right answer' re- 
sponses (p. 166) and look '... at the processes of learning rather than testing the content transmitted' (p. 179). Salmon, however, does not completely shun the opportunities for learning that expert feedback can bring. Salmon suggests that researchers, theorists and other experts can be brought into the discussion forum in their capacity as key players. She writes: "It is exciting for participants to have access to expert views, though they may "go quiet" and let the expert dominate, therefore it is best to keep such sessions down to a week or two' (p. 66).

Another way in which feedback is transformed by e-moderating can be seen in Salmon's approach to e-learning technology which she sees not just as a tool, but also as a social space where people can carry on discussions and conversations and construct networks. She argues that these meetings stimulate curiosity; critical thinking and can promote tolerance and respect towards different opinions and arguments (pp. 17-19). She explains, however, that it is very demanding for e-moderators to facilitate the development of such networks. For example, she writes: 'E-moderators could fall into the trap of thinking of online as one experience whereas each participant will respond according to his or her individual needs' (p. 104). Consequently, Salmon argues that, '...the best e-moderators manage to keep a sense of the composite needs of the group, along with those of a variety of individuals' (p. 110). Traditional authoritative feedback needs to be reconsidered, as Salmon writes: 'Authority and control of the conferences may shift, at least temporarily, from teachers to students... the more frequently as the students become more competent and confident online. Existing hierarchies and relationships can change and even fade' (p. 19). Nonetheless, some participants may be excluded from online discussions. Salmon points out that e-moderators must be ' ... sensitive to any individual or group that appears to be disadvantaged or not participating online' (p. 121). Some participants may voluntarily exclude themselves from participating and simply browse and lurk. Salmon explains that passive participation in discussions has its value in that it gives people time to reflect and get used to communicating online. On occasion, e-moderators might need to intervene to point out the value of lurking to hard-working active participants who might be inclined to regard lurking as a form of negative behaviour. However, Salmon warns, if there are a large number of 'lurkers', then this might signal that the course needs to be redesigned (p. 123). Any kind of harassment must be immediately stopped and e-moderators need to consider the tone of contributions and responses in the online discussions (p. 121). Another situation where participants may be put off from contributing, include conferences that become swamped by one or more dominant individuals (p. 124). In all of these situations, the e-moderator has to make decisions on whether to address these matters in the discussion or quietly and privately outside the main discussion forum.

Salmon also displays a critical awareness of the impact of online networking as a mediated experience. She explains that access problems and lack of technical skill in using the medium can seriously limit the degree of participation in feedback processes. Online networking, she argues, also '... lacks social and contextual cues and is not strictly controlled' (p. 52). She argues that asynchronicity in mediated experiences can be a mixed blessing as regards feedback processes. On the one hand, she explains that the period between log on times allows for proper reflection on topics and messages under discussion (p. 19). On the other hand, it can make it harder for e-moderators to create excitement, rhythm and flow. She writes: 'Key issues are the ability to create clear goals and appropriate challenges, through a vision of the learning outcomes and very short focused steps, good timely feedback and appropriate motivation' (p. 61). Moreover, she explains that: 'Tardiness, rudeness or inconsistency in response to others tend to be forgiven less easily than in a more transient face-to-face setting. Minor complaints can escalate when several individuals in a conference agree with each other and create a visible "marching about with banners" online' (p. 20).

Salmon relates her work on e-moderating to her work on e-tivities by way of her 'five-stage model of teaching and learning online'. She writes: 'Each stage requires participants to 
master certain technical skills... Each stage calls for different e-moderating skills' (p. 29). Let us look at the nature of feedback in each of these five stages.

In stage one, feedback is often technical, concerning getting online and motivation and encouragement to put in the necessary time and effort (p. 31). In stage two, feedback is directed towards enabling and promoting online socialization and explaining how online work will contribute to the topic, the course and, on a wider level, the discipline as a whole (pp. 3334). Here, Salmon argues, feedback should encourage a sense of community - a process that needs to take account of varying cultural backgrounds (p. 37). In stage three, feedback should encourage the exploration on particular aspects of problems and issues. E-moderators, Salmon explains, need to provide feedback that clarifies direction in the mass of messages and encourages the use of relevant content material. At this stage, participants often need help getting used to the messiness of conferencing online (pp. 38-40). It's important that participants do not feel overwhelmed by information (p. 167) and she advises that, generally, feedback should be short in order to keep online communication flowing (p. 192). In this respect, Salmon adds: 'Supportive, formative feedback is motivational and will contribute to modification of participants' thinking... Summative feedback and assessment can be introduced at stage three, especially if aligned with the online processes and achievements' (p. 40). In stage four, Salmon writes, feedback needs to see to it that participants 'appreciate knowledge is not something that is fully "fixed" and can easily be codified and transferred from one person to another' (p. 42). She also warns that it takes skill in interventions by the emoderator to overcome the reluctance of some participants to express controversial views (p. 42). Here too, Salmon suggests, feedback takes the form of woven summaries, which '.. pull together the participants' contributions by, for example, collecting statements and relating them to concepts and theories from the course' (p. 42). It may even be necessary to write several summaries for different parts of an e-tivity and participants themselves may also be asked to write summaries. Summaries that conclude an e-tivity can be used to set the scene for e-tivities that follow. Regarding the relationship between the participants and the emoderator as a teacher or expert at stage four, Salmon writes, '... there is much less of a hierarchy. You could say there is a "flattening" of the communication structure between emoderator and participants... At stage four, we see participants start to become online authors rather than transmitters of information' (p. 45). In stage five, the highest level of achievement in online learning and teaching, Salmon argues, 'e-moderators and participants are essentially using a constructivist approach to learning... Challenge and argument at this stage will foster deeper thinking and reflection' (p. 48).

Regarding formal feedback and assessment, Salmon laments, that some students '... already comment on the irony of spending most of their learning time communicating through their computer, but taking their examination in a formal setting with only a pen and paper for company' (p. 113). She continues: 'Online learning offers more opportunities for students to write for themselves to benefit their own learning and also for each other (rather than "writing for the tutor"). Through networking students can make their writing easily available for review and assessment' (p. 114). According to Salmon, this opens up new opportunities for peer review processes and 'digital portfolios' as tools for both learning and assessment (p. 114).

\section{Discussion and reflection}

Taken together, Gilly Salmon's work on 'e-tivities', the 'five-stage model of teaching and learning online' and 'e-moderating' articulate a new role for communication and its technologies in late modern education. It is a role that allows for a more generative approach to 'preparing for life' and cultivates the ability, in Bauman's words, 
... to live daily and at peace with uncertainty and ambivalence, with a variety of standpoints and the absence of unerring and trustworthy authorities... instilling tolerance of difference and the will to respect the right to be different... fortifying critical and selfcritical faculties and the courage needed to assume responsibility for one's choices and their consequences... training the capacity for 'changing the frames' and for resisting the temptation to escape from freedom, with the anxiety of indecision it brings alongside the joys of the new and unexplored. (2001, p. 138)

It is a role that cannot be '.. . developed in full through that aspect of the educational process which lends itself best to the designing and controlling powers of the theorists and professsional practitioners of education: through the verbally explicit contents of curricula...' (Bauman, 2001, p. 138) that are simply transmitted and mechanically assessed against a fixed outcome. For Salmon, '... the use of e-moderated online learning directly addresses the broadening acceptance and understanding of learning as a socially mediated and constructed process (2003, p. 113). As such, e-moderated online learning constitutes a new learning arena that creates conditions that favour successful deliberative arrangements. First, learners are participants in learning communities in which learning is enriched by information, openended discussion and the monitoring of differing ideas of others. As Thompson argues: '... deliberation thrives on the clash of competing views; nothing is more destructive of the process of deliberation than an orchestrated chorus of opinion which allows for no dissent' (Thompson, 1995, p. 257). Second, on a deeper level, e-moderated online learning allows participants put the 'facticity' of the content of learning to the test and question the grounded principles of taken-for-granted attitudes to what is 'right' and 'proper'. Third, processes of deliberation would not amount to much if discussion forums continuously involved strife and bickering. Summative feedback and woven summaries allow e-moderators and participants to weigh up each other's arguments and draw processes of argument and counterargument to a temporary but practical closure while at the same time keeping them open-ended. Fourth, emoderated online learning creates conditions that favour the recognition of different moral and practical positions and create an arena in which learners can develop a sense of responsibility regarding what they learn.

While praising Salmon's project and efforts to find new paths in e-learning, I also want to offer three points of criticism - not in a negative way, but more as a way of opening up opportunities for their further development. Moreover, these three points of critique provide markers for an ongoing critical engagement with the central problems concerning the impact of net-media on learning.

First, Salmon reiterates four key discontinuities that futurists predict that we will experience this century. These, she writes, '... relate to time and space, mind and body, real and virtual experiences and humans and technologies... their influence on educational institutions is still incalculable but we can be sure there is a serious shake-up going on' (Salmon, 2003, pp. 136137). In order to further develop Salmon's work and to continue a critical engagement with the impact of net-media on learning, I think that we need to unpack this 'incalculable shake up' a good deal further still. Despite the interesting connections that can be made between the development of her e-learning framework and the rise of generative approaches to risk and uncertainty, there are no direct references to the work of Beck, and other social theorists, such as Giddens, in Salmon's work. Salmon's ideas contained in E-learning and E-moderating, together with an ongoing critical engagement with the central problems concerning elearning, would benefit from a more conscious effort to build in the features of an active engagement with risk and uncertainty.

Second, Salmon mentions a group of Scandinavian educators writing about the concept of 'folkbildning'. She explains that 'Nordic folkbildning traditions of over 100 years are based 
on meetings intended as learning and opportunity-generating groups, stimulating curiosity and critical thinking. The democratic nature of the meetings promotes tolerance towards differing opinions and respect for developed arguments. Courses are also structured in this way, and participants are involved in the shaping of their learning processes with others' (p. 17). In order to further develop Salmon's work and to continue a critical engagement with the impact of net-media on learning, I think that we need to reject the idea that we may begin our understanding from a fresh start a good deal further still. Despite her e-tivities and e-moderating bearing so much resemblance to the design, practice and facilitation of problem-based learning, there are no direct references to the wealth of experience built up over the years in this area. Salmon's ideas contained in E-learning and E-moderating, together with an ongoing critical engagement with the central problems concerning e-learning, would benefit from a more rigorous acknowledgement of problem-based learning and facilitation (Savin-Baden, 2003, pp. 90-100).

Third, Salmon asserts: 'The online environment mediates the communication and also shapes it' (2003, p. 19). Throughout her work she demonstrates a deep and rich understanding of the social impact of new media. In order to further develop Salmon's work and to continue a critical engagement with the impact of net-media on learning, I think that we need to deepen our understanding of the role of media and communications in education a good deal further still. Despite the interesting connections that can be made between the development of her elearning framework and the development of generative approaches to the ways in communication technologies facilitate a reorganization of information and interaction across time and space, there are no direct references to the work of Thompson, and other social theorists in this area. Salmon's ideas and an ongoing critical engagement with the central problems concerning e-learning would benefit from a more conscious effort to deal with e-learning technologies as modalities of cultural transmission.

In dealing with these three points of critique as markers for an ongoing critical engagement with the central problems concerning the impact of net-media on learning, we urgently need to remind ourselves of Alvin Toffler's words regarding the impact of digital communication in our lives today. Toffler writes, '... it's not only people and organizations that are connected more tightly, but the different sectors or spheres of the society as well' (Toffler, 1999, p. 5). In a world of learning, these issues concern us all.

\section{Literature}

Barnett, Ronald. “Supercomplexity and the Curriculum”. In: Studies in Higher Education, 25 (3) 2000: 255-265.

Bateson, Gregory. “The logical categories of learning and communication”. In: Steps to an Ecology of Mind. Gregory Bateson Frogmore: Paladin,1973.

Bauman, Zygmunt. “Education: under, for and in spite of postmodernity”. In: The Individualized Society. Zygmunt Bauman (4 ${ }^{\text {th }}$ ed.) Cambridge: Polity, 2001.

Beck, Ulrich. World Risk Society. Cambridge: Polity, 1999.

Bruner, Jerome. Acts of Meaning. Cambridge, MA: Harvard University Press, 1990.

Castells, Manuel. The Internet Galaxy. Reflections on the Internet, Business, and Society. Oxford: Oxford University Press, 2001.

Chapman, Bryan. “Product Shootout: PowerPoint to E-Learning”. In: Training, May 40 (5) 2003: 40-42.

Clegg, Sue; Hudson, Alison; Steel, John. “The Emperor's New Clothes: Globalisation and E-learning in Higher Education”. In: British Journal of Sociology of Education, February, 24 (1) 2003: 39-53.

Dewey, John. Democracy and Education. New York: Macmillan, 1917.

Giddens, Anthony. Central Problems in Social Theory. Action, Structure and Contradiction in Social Analysis. London: Macmillan, 1979. 
Giddens, Anthony. The Constitution of Society. Outline of the Theory of Structuration. Cambridge: Polity, 1984.

Giddens, Anthony. Beyond Left and Right. The Future of Radical Politics. Cambridge: Polity, 1994.

Giddens, Anthony. The Third Way. The Renewal of Social Democracy. Cambridge: Polity, 1998.

Giddens, Anthony. Sociology. Cambridge: Polity, 2001.

Hartman, Jackie; Lewis, Jeffrey S.; Powell, Kare Sterkel. "Inbox Shock: A Study of Electronic Message Volume in a Distance Managerial Communication Course”. In: Business Communication Quarterly, September 65 (3) 2002: 9-28.

Mead, Margaret. Continuities in Cultural Evolution. New Haven: Yale University Press, 1964)

Rantanen, Terhi. “Giddens and the 'G'-word. An interview with Anthony Giddens”. In: Global Media and Communication, 1 (1) 2005: 63-67.

Salmon, Gilly. E-Moderating. The Key to Teaching and Learning Online. London: Kogan Page, 2000.

Salmon, Gilly. E-tivities. The Key to Active Online Learning. London: Kogan Page, 2002.

Salmon, Gilly. E-Moderating. The Key to Teaching and Learning Online. Second edition. London: RoutledgeFalmer, 2003.

Savin-Baden, Magi. Problem-Based Learning in Higher Education: Untold Stories. Buckingham: SRHE and Open University Press, 2000.

Savin-Baden, Magi. Facilitating Problem-Based Learning. Illuminating Perspectives. Buckingham: SRHE and Open University Press, 2003.

Segers, Gary. "Dazed and Confused by E-Learning”. In: T+D, October, 56 (10) 2002: 32-34.

Slevin, James. The Internet and Society. Cambridge: Polity, 2000.

Sloman, Martyn, The E-learning Revolution. From propositions to action. London: Chartered Institute of Personnel and Development, 2001.

Thompson, John B.. Ideology and Modern Culture. Critical Social Theory in the Era of Mass Communication. Cambridge: Polity, 1990.

Thompson, John B.. The Media and Modernity. A Social Theory of the Media. Cambridge: Polity, 1995.

Toffler, Alvin. "Riding the Third Wave. A Conversation with Alvin Toffler”. Tom Johnson and Lawrence Bennigson (interviewers). In: Strategy \& Leadership, July/August/September, 1999.

Vincent, David. The Rise of Mass Literacy. Reading and Writing in Modern Europe. Cambridge: Polity, 2000.

Wadham, Rachel. “Scholarly Communications Crisis”. In: Library Mosaics, November/December, 14 (6) 2003: 23.

Walton, Richard E.. Up and Running: Integration, Information Technology and the Organization. Boston: Harvard Business School Press, 1989.

Williams, Raymond. Television: Technology and Cultural Form. London: Fontana, 1974. 